\title{
Palliative care in lung transplantation
}

\author{
Brandi Braud Scully ${ }^{1,2}$, Eric P. Nolley ${ }^{3}$, Errol L. Bush ${ }^{1}$ \\ ${ }^{1}$ Division of Thoracic Surgery, The Johns Hopkins Hospital, Baltimore, MD, USA; ${ }^{2}$ Johns Hopkins University Berman Institute of Bioethics, \\ Baltimore, MD, USA; ${ }^{3}$ Division of Pulmonary and Critical Care Medicine, The Johns Hopkins Hospital, Baltimore, MD, USA \\ Contributions: (I) Conception and design: All authors; (II) Administrative support: None; (III) Provision of study materials or patients: None; (IV) \\ Collection and assembly of data: None; (V) Data analysis and interpretation: None; (VI) Manuscript writing: All authors; (VII) Final approval of \\ manuscript: All authors. \\ Correspondence to: Brandi Braud Scully, MD, MS. 1800 Orleans, Zayed Tower 7107, Baltimore, MD 21287, USA. Email: bscully4@jh.edu.
}

\begin{abstract}
The role of palliative care in lung transplantation has grown exponentially in the past two decades. From assisting with evaluating and optimizing candidates for transplant, to playing a crucial role in patients requiring extracorporeal cardiopulmonary life support (ECLS) as a bridge to lung transplant, perioperatively, or even during their first year post-transplant, palliative care has been shown to be an effective if underutilized tool in the armamentarium used to care for lung transplant patients. For patients being considered for primary transplantation and for lung transplant recipients, palliative care can decrease symptom burden and help to lessen the psychological distress experienced by patients and family members. For older patients listed for transplant, palliative care can help address cognitive impairment, depression, and frailty. Patients listed for lung re-transplant also benefit from palliative care involvement to address frequent symptom exacerbations, hospitalizations, and higher morbidity and mortality. Even for organ donors and their families, palliative care can facilitate communication and provide support to the family. While palliative care use in lung transplantation may be gradually increasing, further work is necessary to optimally integrate palliative care into lung transplantation. Barriers to lung transplant patients receiving palliative care are multifactorial and include physician, patient, and institutional factors. The potential role of palliative care in every aspect of lung transplantation has made a knowledge of palliative care principles crucial for the lung transplant practitioner. In this review, we will clearly delineate the potential benefit of palliative care for the perioperative lung transplant patient and make an argument for its increased use in this patient population.
\end{abstract}

Keywords: Palliative care; lung transplant

Submitted Jan 21, 2021. Accepted for publication Apr 27, 2021.

doi: 10.21037/apm-21-170

View this article at: http://dx.doi.org/10.21037/apm-21-170

\section{Introduction}

The existence of this review article, and indeed, an entire journal issue dedicated to palliative care and surgery, demonstrates how far our understanding of the potential role for palliative care in lung transplantation has come in the past two decades. Since 2005, when Drs. Molmenti and Dunn published their manuscript entitled "Transplantation and Palliative Care: The Convergence of Two Seemingly Opposite Realities", it has become clear that palliative care has important roles in organ donation, organ failure management, and pre- and post-transplant care (1). The potential role of palliative care in every aspect of lung transplantation has made a knowledge of palliative care principles crucial for the lung transplant practitioner. In this review, we will clearly delineate the potential benefit of palliative care for the perioperative lung transplant patient and make an argument for its increased use in this patient population.

\section{The argument for palliative care in lung transplantation}

In 1990, the World Health Organization defined palliative 
care as "the active total care of patients whose disease is not responsive to curative treatment" in which "control of pain, of other symptoms, and of psychological, social, and spiritual problems, is paramount" (2). The definition was subsequently expanded to describe "an approach that improves the quality of life of patients and their families facing the problems associated with life-threatening illness, through the prevention and relief of suffering by means of early identification and impeccable assessment and treatment of pain and other problems, physical, psychosocial and spiritual" (3). Over the past few decades it has become clear that palliative care improves quality of life and reduces symptom burden for patients with serious illness including cancer and chronic organ failure (4).

There are perhaps few patient populations who stand to benefit more from palliative care than solid organ transplant candidates, who as Crone et al. note, must "balance the hope of prolonged survival, vastly improved health, and optimized quality of life against the possibility of decline and death" (5). Further, lung transplant recipients are a group that stand to particularly benefit, as they experience frequent hospitalizations, respiratory exacerbations, and higher levels of psychological distress including anxiety and depression, compared to other organ recipients $(6,7)$. These patients manage an average of 17 symptoms and, in addition to their family members, report high levels of subjective burden, stress, and need for better communication and access to psychosocial support $(8,9)$.

\section{The potential of palliative care in lung transplantation}

Lung transplant patients can therefore greatly benefit from palliative care involvement, even before they are listed for transplant. As Crone et al. argue, "given that the majority of potentially eligible patients never receive a donor organ, it is reasonable to offer palliative care" to patients awaiting transplant (5). Both the American College of Chest Physicians and the American Thoracic Society recommend that specialty palliative care occur simultaneously with curative or life-extending care $(10,11)$.

In addition, as many have noted, opioid use, an important component of palliative care, has been recommended for end-stage lung disease by multiple societies including The Canadian Thoracic Society, British Thoracic Society, the American Thoracic Society and the American College of Chest Physicians, as well as the National Institute for Health and Care Excellence (11-14).
The American Thoracic Society in their Clinical Policy Statement Regarding Palliative Care recommends that palliative care should begin when a patient becomes symptomatic (11).

However, although many like McKenna et al. have argued that palliative care should be considered an integral part of the treatment of patients undergoing lung transplantation, few programs have incorporated palliative care into the routine evaluation or management of these patients (15). In addition, palliative care has not been written into the guidelines for the treatment of lung transplant patients for any of the major transplant societies. Much work remains to be done before the potential of palliative care in the perioperative care of lung transplant patients has been reached.

\section{Palliative care in lung transplantation}

\section{Patients awaiting lung transplantation}

Patients listed for lung transplantation remain a particularly challenging group of patients, with high symptom burden as well as psychological distress associated with both the disease and the uncertainty of being on the waitlist. They experience what Freeman et al. call "a complex constellation of physical, psychosocial, and emotional symptoms, including dyspnea, cough, anxiety, depression, and insomnia" (16). The particular benefits of palliative care in this patient population include the providing of better coping skills, support for caregivers, the ability to address this existential distress, as well as a focus on symptom management. This is especially important in the highest risk populations, including older patients, hospitalized patients awaiting lung transplantation, patients mechanically bridged to transplantation, and re-transplant candidates.

However, many barriers remain to the routine use of palliative care in lung transplant candidates. Colman et al. name several specific barriers, including patient fear of abandonment by the transplant team, lack of access to supportive services, and concern over use of opioids by palliative care in symptom management, both due to the potential for opioid dependence and opioid-related respiratory depression (17). These perceived barriers result in delays to consultation of palliative care until the end of a patient's life and result in many end-stage lung disease patients dying in intensive care units receiving aggressive care (6,18-20).

In contrast to this widespread belief, Colman et al. 
have shown that outcomes of lung transplant candidates referred for co-management by palliative care can be safely provided without compromising eligibility or exercise tolerance (17). In their review of 308 lung transplant candidates, $20.7 \%$ were referred to palliative care, and of these, $92 \%$ were prescribed opioids for dyspnea. Many providers are hesitant to consider transplantation in recipients with moderate or greater amounts of opioids because of concerns for challenging postoperative pain management with respiratory suppression or increasing rates of opioid dependence. However, of the $47 \%$ of patients who went on to receive a lung transplant, only 7 patients $(23 \%)$ required an opioid prescription one month post-discharge. Colman et al. therefore argue that not only does palliative care not compromise a patient's ability to go on to lung transplantation, it may also improve a patient's baseline condition, improving their chance of a successful perioperative course (17).

Colman et al. describe an algorithm for symptom management with a palliative care consult involving attention to symptom control, advance care planning, and emotional as well as spiritual support. For the control of dyspnea in patients listed for lung transplant, they utilize a low-dose oral opioid regiment (morphine $2.5-5 \mathrm{mg}$ or hydromorphone 0.5 to $1 \mathrm{mg}$ PRN) with a planned transition to standing immediate-release opioids or sustained-release opioids over days to weeks, titrating the total daily dose to subjective symptom relief and side effects (17). Their routine palliative care efforts also include patient valuescentered discussions that encompass cardiopulmonary resuscitation and life-sustaining treatments (17).

Transplant clinicians have recently advocated for increased utilization of outpatient palliative care for patients with end-stage non-malignant lung disease awaiting transplantation. Freeman et al. recently evaluated the effect of an outpatient transplant palliative care clinic on patients awaiting transplantation and found that symptom burden was improved (16). As seen in other studies, there were no opioid-related morbidities, and the majority of patients prescribed opioids as part of the palliative care treatment (62/65 patients) discontinued opioids post-transplant; the three patients who did not were chronic pain patients on opioids prior to palliative care consultation (16). Wentlandt et al. argue that an ambulatory palliative care clinic is a useful model to improve symptom burden in lung transplant patients prior to transplantation and have outlined the development and structure of a Transplant Palliative Care Clinic (21). They argue that there is a need for palliative care teams that span the inpatient and outpatient settings and recommend early referral to palliative care services as well as full integration of transplant and palliative care programs (21).

\section{Patients who are hospitalized pre-transplant}

Transplanting acutely ill patients is becoming more common, with as many as one-third of patients who receive a lung transplant being hospitalized prior to transplantation (22). In Singer et al's recent study, of the $33 \%$ of patients already hospitalized prior to transplant, $11 \%$ were intubated and $9 \%$ received extracorporeal cardiopulmonary life support, or ECLS (23). Importantly, acutely ill patients had the same likelihood of benefit in quality of life from lung transplantation as patients coming in from home (23). Nevertheless, given that patients hospitalized pre-transplant are likely to have more severe symptomatology and greater risk of death on the waitlist, they would stand to greatly benefit from the involvement of palliative care. As noted by Colman et al., palliative care involvement has often been delayed in these patients until almost the very end of life, suggesting there is much room for improvement in the involvement of palliative care in this patient population (17).

\section{Patients on extracorporeal cardiopulmonary life support as bridge to lung transplant}

Extracorporeal cardiopulmonary life support, or ECLS, is increasingly used among patients awaiting lung transplant and deserves special mention (24). In some cases, ECLS can be initiated using a dual lumen cannulation strategy, allowing these patients to be bridged nonintubated, as well as ambulatory, and for physiotherapy to be performed while waiting for transplant $(24,25)$. For these patients at our institution, a bicaval dual lumen catheter is inserted into the right jugular vein using echocardiographic guidance, usually bedside in the intensive care unit. We have used both Avalon and Crescent cannulas (VV ECMO, Avalon Cannula, Maquet, Germany and Crescent Jugular Dual Lumen Catheter, manufactured by MC3 Cardiopulmonary, Dexter, Michigan and distributed by Medtronic, Dublin, Ireland). The ability to avoid cannulating the groin with this technique allows patients to ambulate and work with physical and occupational therapy while awaiting lung transplantation.

Many have advocated for palliative care to be routinely involved in ECLS consults, in order to reduce symptom 
burden, facilitate communication and decision-making, and alleviate patient and family suffering (25). As the use of ECLS bridge to lung transplant increases, palliative care utilization for these patients has increasing potential to improve the care of these patients.

\section{Older patients listed for lung transplant}

The average age of lung transplant recipients is increasing (22). Moreover, patients aged 65 and older have been shown to have a median survival after lung transplantation of only 3.5 years, which is three years less than that for patients younger than 50 (22). Singer et al. have also shown that patients older than 65 derive less health-related quality of life (HRQL) from lung transplantation (23). They point to recent studies while postulating that frailty, depression, and cognitive impairment may play a role (26-28). Importantly, almost one-fourth of Singer et al.'s patient cohort was age 65 or older (23). With their known shorter life expectancy and smaller gains in quality of life after lung transplantation, the elderly patient population may benefit even more from the involvement of palliative care in the perioperative period.

\section{Patients listed for lung re-transplantation}

Although they represent a small subset of lung transplant patients, patients who are listed for lung retransplantation may need additional support from palliative care services. They have higher morbidity and mortality compared to patients undergoing primary transplant, and experience frequent hospitalizations and symptom exacerbations $(29,30)$. Ivarsson et al. followed the experiences of supportive care for seven patients listed for lung retransplantation, four of whom went on to die on the waiting list (31). They conclude that while hope for the future is paramount for these patients, ongoing support with "all facilities of palliative care" is crucial for both patients and their family members, particularly those patients with dependent children who may have additional emotional needs (31).

With both more elderly and acutely ill patients, including those requiring re-transplantation, being listed and undergoing lung transplant, there is great potential for palliative care principles of providing coping skills, support for caregivers, symptom management and quality of life discussions to make an impact in patient outcomes.

\section{The early postoperative period}

Early after transplantation, palliative care can have a significant impact on patient well-being, and in fact, this may be a key period during which the involvement of palliative care can improve patient outcomes. While posttransplant patients usually enjoy a temporary improvement in their symptom burden as well as quality of life, their psychosocial health can still suffer (27). While Rosenberger et al. characterized early postoperative lung transplant psychosocial health as below average, Singer et al. showed that most lung transplant recipients had enduring improvements in quality of life and psychological quality of life remained on average within population norms (23). However, Singer et al. found that one-fifth of patients experience a decline in mental quality of life in the first post-transplant year, with older patients being at greatest risk (23). These studies suggest that the early postoperative period is a crucial time for the involvement of palliative care, with the potential to alter difficult patient trajectories.

Further strengthening this argument is the knowledge gained from recent studies examining the early posttransplant course, which have concluded that a difficult early postoperative period is associated with longitudinally worse quality of life, and in particular a worse mental quality of life. Seiler et al.'s recent work demonstrated the difficulty of the early post-transplant adjustment period, during which severe adverse effects of treatment, physical complaints or medication side effects, fear of organ rejection, and restriction in everyday life emerged as the most common patient concerns (32). These concerns were shown to be consistent over the first six months after transplant, and the difficulty of this initial post-transplant period has been seen in other studies $(33,34)$.

In addition, psychological co-morbidities of post traumatic stress disorder, depression, and anxiety are common in this patient population, and depression in particular is worrisome as it is associated with worse outcomes, including survival. Smith et al. have shown that survival is linked to psychosocial well-being in lung transplant patients (35), and this pattern can be seen in other transplant patients: importantly, bone marrow transplant recipients for AML follow a similar pattern of declining quality of life and increasing psychological and symptom burden $(36,37)$. One recent randomized controlled trial of integrated palliative care for bone marrow transplant recipients demonstrated reduced decline 
in quality of life and improvement in psychological burden both in the immediate perioperative period, and the benefits of palliative care were still seen 6 months later $(36,37)$.

\section{The first post-transplant year}

Nolley et al. reviewed 597 lung transplant patients at a tertiary medical center over five years, for whom 2,818 specialty palliative care encounters were undertaken (38). $64 \%$ of these occurred within the first year, with a median time of consultation 0.53 years post-transplant and the majority of consultations were for symptom management and psychosocial support (38). The majority of palliative care consults occurring within the first year after transplantation belies the distress that many transplant recipients experience immediately after transplantation, including from side effects related to immunosuppression, pain, postoperative cognitive dysfunction, depression and post-traumatic stress disorder. This, as well as the distress associated with adjusting to the challenges of post-transplant life, has been seen in many recent studies $(23,35,38,39)$.

The majority of lung transplant patients are rehospitalized during the first transplant year, and palliative care remains crucial as re-hospitalization is associated with lower perception of general health, lower physical and social functioning, and greater bodily pain (40). Pneumonia, bronchitis, shortness of breath, graft rejection, respiratory failure, and pleural effusions have been shown to be leading causes of unplanned readmissions (41). The first year after lung transplantation is high risk for unplanned readmissions regardless of the initial indication for transplant, and patients readmitted within 60 days after their index hospitalization for lung transplantation were 1.6 times more likely to die than those readmitted later than 60 days (41). The high rate of re-hospitalization in the first posttransplant year, as well as the psychological distress that accompanies it, provides many opportunities for palliative care to improve patient outcomes.

\section{Palliative care in organ donation}

Palliative care has been shown to be effective in the treatment of organ donors and the care of their families. Kelso et al. describe the use of palliative care for endof-life care and family support in organ donation after cardiac death (DCD), with palliative care skills including communication, coordination of care and skillful ventilator withdrawal proving beneficial (42). Once the DCD protocol is initiated at their institution, the palliative care team is consulted with the goals of managing the patient's physical care, advocating for and providing comfort for the family, and to continue the care of the patient if they survive beyond 90 minutes (42).

In addition to palliative care providing support to patients who become donors and their families, the Hospice and Palliative Nursing Association (HPNA) supports palliative care practitioners promoting organ and tissue donation when possible (43). In their position statement, they argue that palliative care providers and hospices should both educate patients and families on the need for organ and tissue donation and partner with organ procurement organizations to help improve organ and tissue donation as appropriate (43).

\section{Continued barriers to thoracic transplant patients receiving palliative care}

While transplant candidates and recipients likely have significant palliative care needs, they still rarely receive palliative care. Barriers to lung transplant patients receiving palliative care pre or post-transplant are multifactorial, including physician, patient, and institutional factors. In their survey of 74 transplant and palliative care clinicians from 18 transplant centers in 2009, Song et al. identified multiple barriers to post-transplant palliative care (30). Barriers for transplant clinicians included the misconception that palliative care was equivalent to end-of-life care, uncertainty about recipients' prognoses, the perception that palliative care precludes further aggressive treatment, and difficulty discussing palliative care with families. For the palliative care clinicians, barriers included a perceived lack of understanding by referring colleagues regarding the scope of palliative care services and the misconception that palliative care precludes further treatment (30).

Similarly, in 2013 Colman et al. assessed barriers to palliative care referral pre-transplant, identifying patient and family factors (unrealistic expectations of patients and family regarding survival, unwillingness to plan end-oflife care, concerns about abandonment or inappropriate care after enrollment in a palliative care program, and family disagreements about care goals), physician factors (competing time demands and seemingly contradictory goals of transplant versus palliative care), and institutional factors (requirements for weight loss or specific BMI requirements) (44). Additional barriers to referral may include concerns about 1 year post-transplant survival and 
Table 1 Palliative care in lung transplantation

\begin{tabular}{|c|c|}
\hline Groups that can benefit & Palliative care treatment \\
\hline \multirow{4}{*}{$\begin{array}{l}\text { Patients awaiting lung } \\
\text { transplant and patients } \\
\text { hospitalized } \\
\text { pre-transplant }\end{array}$} & Need for emotional and spiritual support \\
\hline & High levels of psychological distress \\
\hline & Need for advance care planning \\
\hline & High symptom burden \\
\hline \multirow[t]{2}{*}{$\begin{array}{l}\text { Patients on ECMO } \\
\text { bridge to transplant }\end{array}$} & $\begin{array}{l}\text { Facilitate communication and } \\
\text { decision-making }\end{array}$ \\
\hline & Alleviate patient and family suffering \\
\hline \multirow{3}{*}{$\begin{array}{l}\text { Older patients listed } \\
\text { for transplant }\end{array}$} & Cognitive impairment \\
\hline & Depression \\
\hline & Frailty \\
\hline \multirow[t]{4}{*}{$\begin{array}{l}\text { Patients listed for lung } \\
\text { re-transplant }\end{array}$} & $\begin{array}{l}\text { High emotional needs for patients, } \\
\text { dependent children and other family } \\
\text { members }\end{array}$ \\
\hline & Frequent symptom exacerbations \\
\hline & Higher morbidity and mortality \\
\hline & Frequent hospitalizations \\
\hline \multirow{4}{*}{$\begin{array}{l}\text { Patients in the early } \\
\text { postoperative period } \\
\text { after } \\
\text { transplant }\end{array}$} & Decline in mental quality of life \\
\hline & PTSD, depression, and anxiety \\
\hline & Medication side effects \\
\hline & Fear of organ rejection \\
\hline \multirow[t]{7}{*}{$\begin{array}{l}\text { Patients in the first } \\
\text { year post-transplant }\end{array}$} & $\begin{array}{l}\text { Side effects related to } \\
\text { immunosuppression }\end{array}$ \\
\hline & Postoperative cognitive dysfunction \\
\hline & PTSD \\
\hline & Symptom management \\
\hline & Psychosocial support \\
\hline & Depression \\
\hline & Pain \\
\hline
\end{tabular}

ECMO, extracorporeal membrane oxygenation; PTSD, posttraumatic stress disorder.

concerns about potentially addicting medications (38).

Interestingly, a recent in-depth interview study of transplant pulmonologists view of palliative care suggests that some barriers have changed. In contrast to the earlier work of Song, Nolley et al. found that transplant pulmonologists accurately distinguish between palliative care and hospice care as they describe palliative care as a specialty that aims to improve quality of life and hospice care as end of life care (38). Moreover, transplant pulmonologists views of transplant, and not their views of palliative care, were associated with different referral practices. Those that referred to palliative care while pursuing disease directed therapies described transplant as a temporary solution while those that referred once disease directed therapies were exhausted described transplant as survival focused. This finding echoes that of Colman et al. and suggest that despite differentiating between palliative care and hospice care, some transplant providers may still consider the treatment goals of palliative care and transplant.

Both Colman and Song recommend several strategies to overcome these barriers, including more collaboration between transplant and palliative care programs, the development of ambulatory services, and routine advanced care planning for listed patients $(30,45)$. While palliative care likely remains widely underutilized, some recent trends are encouraging. Nolley et al. reported increasing utilization of palliative care for lung transplant recipients at a center with robust inpatient and outpatient palliative care services, with inpatient utilization increasing from $23 \%$ in 2010 to $42 \%$ in 2015 , and outpatient utilization increasing from $2 \%$ in 2010 to $16 \%$ in 2015 (38). As has been argued for lung transplant candidates on ECLS, and given the clear benefit of palliative care perioperatively as has been delineated here, an argument can be made for routine use of palliative care to relieve symptoms, improve communication and decision-making, and alleviate psychological distress for the patient and family in all lung transplant candidates (25). We would argue that embedding palliative care into the lung transplant team, often referred to as integrated palliative care, offers the greatest opportunity to improve the use of palliative care in these patients, and would provide the greatest impact for this patient population.

\section{Conclusions}

We have shown the wide potential benefit of palliative care for perioperative lung transplant candidates, both broadly as well as for the highest risk populations, including older patients, hospitalized patients awaiting lung transplantation, patients mechanically bridged to transplantation, and retransplant candidates (Table 1). This care can be provided across patient settings, both inpatient and outpatient, and the argument for routine palliative care for these patients is bolstered by recent studies demonstrating a link between a difficult early postoperative period and longitudinally 
worse quality of life, including psychosocial quality of life $(28,32,33)$. While there is still significant work to be done, the great potential for palliative care to further improve perioperative outcomes for lung transplant recipients justifies a robust continued effort to optimally integrate palliative care into lung transplantation.

\section{Acknowledgments}

Funding: This work was supported by the Hecht-Levi postdoctoral fellowship at the Berman Institute of Bioethics at the Johns Hopkins University.

\section{Footnote}

Provenance and Peer Review: This article was commissioned by the Guest Editors (Fabian M. Johnston and Ana Berlin) for the series "Palliative Care and Surgery" published in Annals of Palliative Medicine. The article has undergone external peer review.

Conflicts of Interest: All authors have completed the ICMJE uniform disclosure form (available at https://apm.amegroups. com/article/view/10.21037/apm-21-170/coif). The series "Palliative Care and Surgery" was commissioned by the editorial office without any funding or sponsorship. ELB reports that he is a medicolegal consultant for lung failure and occupational or environmental inhalation exposures. The authors have no other conflicts of interest to declare.

Ethical Statement: The authors are accountable for all aspects of the work in ensuring that questions related to the accuracy or integrity of any part of the work are appropriately investigated and resolved.

Open Access Statement: This is an Open Access article distributed in accordance with the Creative Commons Attribution-NonCommercial-NoDerivs 4.0 International License (CC BY-NC-ND 4.0), which permits the noncommercial replication and distribution of the article with the strict proviso that no changes or edits are made and the original work is properly cited (including links to both the formal publication through the relevant DOI and the license). See: https://creativecommons.org/licenses/by-nc-nd/4.0/.

\section{References}

1. Molmenti EP, Dunn GP. Transplantation and palliative care: The convergence of two seemingly opposite realities. Surg Clin North Am 2005;85:373-82.

2. World Health Organization. Cancer pain relief and palliative care: report of a WHO expert committee. World Health Organ Tech Rep Ser 1990;804:1-75.

3. World Health Organization. WHO definition of Palliative Care. Available online: who.int/news-room/fact-sheets/ detail/palliative-care. Accessed November 30, 2020.

4. Kavalieratos D, Corbelli J, Zhang D, et al. Association between palliative care and caregiver outcomes: A systematic review and meta-analysis. JAMA 2016;316:2104-14.

5. Crone CC, Marcangelo MJ, Shuster JL. An approach to the patient with ogan failure: transplantation and end-of-life treatment decisions. Med Clin North Am 2010;94:1241-54.

6. Song MK, De Vito Dabbs A, Studer SM, et al. Course of illness after the onset of chronic rejection in lung transplant recipients. Am J Crit Care 2008;17:246-253.

7. Stilley CS, Dew MA, Stukas AA, et al. Psychological symptom levels and their correlates in lung and heart-lung transplant recipients. Psychosomatics 1999;40:503-9.

8. De Vito Dabbs A, Dew MA, Stilley CS, et al. Psychosocial vulnerability, physical symptoms and physical impairment after lung and heart-lung transplantation. J Heart Lung Transplant 2003;22:1268-75.

9. Ullrich G, Jansch H, Schmidt S, et al. Consulting the "experts": A pilot study on perceptions of professional support among lung transplant recipients and accomipanying relatives. Prog Transplant 2005;15:115-22.

10. Selecky PA, Eliasson CAH, Hall RI, et al. Palliative and end-of-life care for patients with cardiopulmonary diseases: American College of Chest Physicians position statement. Chest 2005;128:3599-610.

11. Lanken PN, Terry PB, Delisser HM, et al. An official American Thoracic Socieety clinical policy statement: palliative care for patients with respiratory diseases and critical illnesses. Am J Respir Crit Care Med 2008;177:912-27.

12. Marciniuk DD, Goodridge D, Hernandez P, et al. Managing dyspnea in patients with advanced chronic obstructive pulmonary disease: a Canadian Thoracic Society clinical practice guideline. Can Respir J 2011;18:69-78.

13. Mahler DA, Selecky PA, Harrod CG, et al. American College of Chest Physicians consensus statement on the mangement of dyspnea in patients with advanced lung or heart disease. Chest 2010;137:674-91. 
14. Chronic obstructive pulmonary disease: management of chronic obstructive pulmonary disease in adults in primary and secondary care. National Institute for Health and Care Excellence (NICE), Available online: https:www.nice.org. uk/guidance/cg101. Accessed November 30, 2020.

15. McKenna M, Clark SC. Palliative care in cardiopulmonary transplantation. BMJ Support Palliat Care 2015;5:427-34.

16. Freeman N, Le LW, Singer LG, et al. Impact of a transplant palliative care clinic on symptoms for patients awaiting lung transplantation. J Heart Lung Transplant 2016;35:P1037-9.

17. Colman R, Singer LG, Barua R, et al. Outcomes of lung transplant candidates referred for co-management by palliative care: A retrospective case series. Palliat Med 2015;29:429-35.

18. Janssen DJ, Spruit MA, Does JD, et al. End-of-life care in a COPD patient awaiting lung transplantation: a case report. BMC Palliat Care 2010;9:6.

19. Ferrin M, Happ MB, and Kagan SH. Palliative care and lung transplantation: conflict or continuum? Am J Nurs 2001;101:61-6.

20. Lindell KO, Liang Z, Hoffman LA, et al. Palliative care and location in death in decedents with idiopathic pulmonary fibrosis. Chest 2015;147:423-9.

21. Wentlandt K, Dall'Osto A, Freeman N, et al. The Transplant Palliative Care Clinic: an early palliative care model for patients in a transplant program. Clin Transplant 2016;30:1591-6.

22. Yusen RD, Edwards LB, Kucheryavaya AY, et al. The Registry of the International Society for Heart and Lung Transplantation: Thirty-second Official Adult Lung and Heart-Lung Transplantation Report-2015; Focus Theme: Early Graft Failure. J Heart Lung Transplant 2015;34:1264-77.

23. Singer JP, Katz PP, Soong A, et al. The effect of lung transplantation on health related quality of life in the era of lung allocation score: A U.S. prospective cohort study. Am J Transplant 2017;17:1334-45.

24. Hoetzenecker K, Donohoe L, Yeung JC, et al. Extracorporeal life support as a bridge to lung transplantation--experience of a high-volume transplant center. J Thorac Cardiovasc Surg 2018;155:1316-1328.e1.

25. Koons B, Sibert J. Extracorporeal membrane oxygenation (ECMO) as a bridge to lung transplantation: considerations for critical care nursing practice. Crit Care Nurse 2020;40:49-57.

26. Dew MA, Rosenberger EM, Myaskovsky L, et al. Depression and anxiety as risk factors for morbidity and mortality after organ transplantation: A systematic review and meta-analysis. Transplantation 2015;100:988-1003.

27. Rosenberger EM, DiMartini AF, DeVito Dabbs AJ, et al. Psychiatric predictors of long-term transplant-related outcomes in lung transplant recipients. Transplantation 2016;100:239-47.

28. Smith PJ, Blumenthal JA, Carney RM, et al. Neurobehavioral functioning and survival following lung transplantation. Chest 2014;145:604-11.

29. Kawut SM, Lederer DJ, Kshavjee S, et al. Outcomes after lung retransplantation in the modern era. Am J Respir Crit Care Med 2008;177:114-20.

30. Song MK, De Vito Dabbs A, Studer SM, et al. Palliative care referrals after lung transplantation in major transplant centers in the United States. Crit Care Med 2009;37:1288-92.

31. Ivarsson B, Ingemansson R, Sjoberg T. Experiences of supportive care when waiting for a lung re-transplantation. SAGE Open Med 2017;5:2050312117697151.

32. Seiler A, Jenewein J, Martin-Soelch C, et al. Posttransplant outcome-clusters of psychological distress and health-related quality of life in lung transplant recipients. Swiss Med Wkly 2015;145:w14236.

33. Seiler A, Klaghofer R, Drabe N, et al. Patients' early post-operative experiences with lung transplantation: A longitudinal qualitative study. Patient 2016;9:547-57.

34. Goetzmann L, Seiler A, Benden C, et al. Transplantation experience as a predictor for quality of life during the first six months after lung transplantation. Clin Transplant 2018;32:e13393.

35. Smith PJ, Snyder LD, Palmer SM, et al. Depression, social support, and clinical outcomes following lung transplantation: a single-center cohort study. Transpl Int 2018;31:495-502.

36. El-Jawahri A, LeBlanc T, VanDusen H, et al. Effect of inpatient palliative care on quality of life 2 weeks after hematopoietic stem cell transplantation: A randomized clinical trial. JAMA 2016;316:2094-103.

37. El-Jawahri A, Traeger L, Greer JA, et al. Effect of inpatient palliative care during hematopoietic stem-cell transplant on psychological distress 6 months after transplant: Results of a randomized clinical trial. J Clin Onc 2017;35:3714-21.

38. Nolley EP, DeSensi R, Nouraie M, et al. Characteristics, trends, and predictors of specialty palliative care utilization after lung transplantation. J Palliat Med 2019;22:1092-8.

39. Alrawashdeh M, Zomak R, Dew MA, et al. Pattern and predictors of hospital readmission during the first year after lung transplantation. Am J Transplant 
2017; 17:1325-33.

40. Vasiliadis HM, Collet JP, Poirier C. Health-related qualityof-life determinants in lung transplantation. J Heart Lung Transplant 2006;25:226-33.

41. Lushaj E, Julliard W, Akhter S, et al. Timing and frequency of unplanned readmissions after lung transplantation impact long-term survival. Ann Thorac Surg 2016;102:378-84.

42. Kelso CM, Lyckholm LJ, Coyne PJ, et al. Palliative care consultation in the process of organ donation after cardiac death. J Palliat Med 2007;10:118-26.

Cite this article as: Scully BB, Nolley EP, Bush EL. Palliative care in lung transplantation. Ann Palliat Med 2022;11(2):927-935. doi: 10.21037/apm-21-170
43. Departments: HPNA Position Statement: The role of palliative care in donation for transplantation. J Hops Palliat Nurs 2019;21:E16-E18.

44. Colman RE, Curtis JR, Nelson JE, et al. Barriers to optimal palliative care of lung transplant candidates. Chest 2013;143:736-43.

45. Colman R, Singer LG, Barua R, et al. Characteristics, interventions, and outcomes of lung transplant recipients co-managed with palliative care. J Palliat Med 2015;18:266-9. 